Taieb Kassab Institute of Orthopedic Surgery and Traumatology, Rheumatolgy, Manouba, Tunisia; ${ }^{3}$ Mohamed Taieb Kassab Institute of Orthopedic Surgery and Traumatology, Radiology, Manouba, Tunisia

Background: Rheumatoid arthritis (RA) is chronic inflammatory rheumatism characterized by an independent cardiovascular (CV) risk. The screening of carotid intima-media thickness (IMT) in the common carotid artery appears to be a marker of atherosclerosis and is used as a specific tool for CV risk assessment. Objectives: The main of this study was to determine the most associated US sites with $\mathrm{CV}$ risk in RA.

Methods: The present study is a prospective study conducted on Tunisian RA patients in rheumatology department of Mohamed Kassab University Hospital (March and December 2020). The characteristics of the patients and those of the disease were collected. The measurement of cIMTwas done using high-resolution B-mode carotid US with a Philips machine with the patient in supine position, according to AmericanSociety of Echocardiography guidelines. The carotid bulb below itsbifurcation and the internal and external carotid arteries were evaluated bilaterally with gray scale, spectral and color Doppler ultra-sonography using proprietary software for carotid arterymeasurements.IMT was measured using the two inner layers of the commoncarotid artery and an increased IMT was defined as $\geq 0.9 \mathrm{~mm}$. The CV risk at 10 years was calculated by the SCORE index.

Results: Forty-seven patients were collected, of which $78.7 \%$ were women. The mean age was $52.5 \pm 11.06$ years. The rheumatoid factor (RF) was positive in $57.8 \%$ of cases, and anti-citrullinated peptide antibodies (ACPA) were positive in $62.2 \%$ of cases. RA was erosive in $81.6 \%$ of cases. Hypertension (hypertension) was present in $14.9 \%$ of patients and diabetes in $12.8 \%$ of patients. Nine patients were active smokers. The mean IMT in the left common carotid (LCC) was $0.069 \pm 0.015$, in the left internal carotid (LIC) was $0.069 \pm 0.015$, in the left external carotid (LEC) was $0.060 \pm 0.023$. The mean IMT was $0.068 \pm 0.01$ in the right common carotid (RCC), $0.062 \pm 0.02$ in the right internal carotid (RIC), and $0.060 \pm 0.016$ in the right external carotid (REC). The mean SCORE index of CV risk was $2 \pm 2.81$ [0-11.6]. CV risk was significantly associated with the IMTs for LIC $(p=0.029 ; r=0.374)$, LEC $(p=0.04 ; r=0.480)$, and REC $(p=0.016 ; r=0.408)$. No association was found between the IMT in the LCC $(p=0,361 ; r=0,162)$, neither in the RCC $(p=0,438 ; r=0,140)$ nor the RIC $(p=0,670 ; r=0,077)$.

Conclusion: In our study, IMT is strongly associated with score index, especially in carotid bifurcation. However, IMT measured in common carotid does not reflect a cardiovascular risk at 10-years.

REFERENCES:

[1] S. Gunter and al. Arterial wave reflection and subclinical atherosclerosis in rheumatoid arthritis. Clinical and Experimental Rheumatology 2018; 36: Clinical E.xperimental.

[2] Aslan and al. Assessment of local carotid stiffness in seronegative and seropositive rheumatoid arthritis. SCANDINAVIAN CARDIOVASCULAR JOURNAL, 2017.

[3] Martin I. Wah-Suarez and al, Carotid ultrasound findings in rheumatoid arthritis and control subjects: A case-control study. Int J Rheum Dis. 2018;1-7.

Disclosure of Interests: None declared

DOI: 10.1136/annrheumdis-2021-eular.4004

\section{AB0187 \\ PREVALENCE, RISK FACTORS, AND TREATMENT MODALITIES OF ATLANTOAXIAL DISLOCATION IN RHEUMATOID ARTHRITIS}

K. Maatallah ${ }^{1}$, S. Miri ${ }^{1}$, H. Ferjani ${ }^{1}$, D. Ben Nsib ${ }^{1}$, W. Triki', A. Dallegi', D. Kaffel', W. Hamdi'. ${ }^{1}$ Mohamed Kassab Institute of Orthopedics, Rhumatology, Manouba, Tunisia

Background: Cervical spine involvement is common in patients with rheumatoid arthritis (RA). The most common abnormality is atlantoaxial dislocation (AAD). It may lead to severe neurological symptoms and even death. Currently, there is a lack of consensus on the best approach to treatment.

Objectives: We investigated the prevalence of and risk factors for AAD in patients with RA, as well as its relationship to treatment modalities.

Methods: We conducted a cross-sectional study including 224 patients with RA. All patients fulfilled the 2010 American College of Rheumatology/European League Against Rheumatism RA classification criteria. Radiographs of the cervical spine included lateral views taken in flexion, extension, neutral position of the neck, anteroposterior and odontoid projection view. Patients were divided into two groups: (G1) a group with AAD and (G2) without ADD. We compared clinical, radiological, and laboratory findings between the two groups, as well as the treatments used: Steroid therapy, classic and biologic disease-modifying anti-rheumatic drugs (DMARDs). Structural joint damage was assessed with the Sharp/van der Heijde radiographic method. Functional impairment was assessed using the Health Assessment Questionnaire (HAQ). We used Statistical Package for Social Sciences (SPSS) 22.0 to analyze the results. The level of statistical significance was set at 0.05 .
Results: ADD was present in $16 \%$ of the cases $(n=36)$. Female predominance was noted, with a sex ratio of $0.25(\mathrm{p}=0.530)$. The mean age was $58 \pm 12$ years, with no significant difference between groups $(p=0.146)$. The mean disease duration was significantly higher in $\mathrm{G} 1$ (11.5 \pm 10.5 years versus $5.9 \pm 6.3$, $p=0.004$ ). A noticeable relationship between $A A D$ and immunopositivity was found: rheumatoid factor (RF) was present in $86.1 \%$ of the cases in $\mathrm{G} 1$ versus $67.5 \%$ in $\mathrm{G} 2(\mathrm{p}=0.025)$. Anti-citrullinated protein antibodies (ACPA) were present in $86.1 \%$ of the cases in $\mathrm{G} 1$ versus $64.8 \%$ in $\mathrm{G} 2(\mathrm{p}=0.012)$. We found a significant difference between AAD and disease activity assessed by DAS28-VS ( $5.8 \pm 1.3$ in $\mathrm{G} 1$ versus $5.3 \pm 1.6$ in $\mathrm{G} 2, \mathrm{p}=0.027$ ). AAD was significantly associated with more structural joint damage: erosions $(121.1 \pm 60.9$ in $\mathrm{G} 1$ versus $61.8 \pm 56.5$ in $\left.\mathrm{G} 2, \mathrm{p}<10^{-3}\right)$, joints space narrowing $(77.4 \pm 47.4$ in $\mathrm{G} 1$ versus $38.7 \pm 40$ in $\mathrm{G} 2$, $\left.p<10^{-3}\right)$, Sharp/van der Heijde radiographic score $(190.2 \pm 103.1$ in $\mathrm{G} 1$ versus $100.1 \pm 90.6$ in $\left.\mathrm{G} 2, \mathrm{p}<10^{-3}\right)$. Hip involvement was more frequent in $\mathrm{G} 1(22.2 \%$ versus $9.4 \%$ in $\mathrm{G} 2, \mathrm{p}=0.038$ )

HAQ score was higher in $\mathrm{G} 1(1.8 \pm 0.7$ versus $1.2 \pm 1, \mathrm{p}=0.002)$.

Seventy-five percent of patients in $\mathrm{G} 1$ had received methotrexate versus $82.3 \%$ in $\mathrm{G} 2(\mathrm{p}=0.301)$. The mean duration of methotrexate therapy was longer in $\mathrm{G} 1$ $(24.6 \pm 23.5$ versus $18 \pm 24$ months, $p=0.015)$. $G 1$ patients received a higher mean dose and cumulative dose of methotrexate: $13.2 \pm 3.5 \mathrm{~g} /$ week versus $11.8 \pm 4.4 \mathrm{~g} /$ week ( $p=0.048)$, and $6.5 \pm 6.8$ versus $4.8 \pm 8.5(p=0.025)$, respectively.

Thirty-five percent of patients in G1 had received corticosteroids versus $25 \%$ in $\mathrm{G} 2(p=0.217)$. Patients in $\mathrm{G} 1$ had a significantly longer duration of steroid therapy: $17.8+20.2$ versus $13.3+24.3$ months $(p=0.22)$. The mean dose of corticosteroids was similar between the two groups: $6.9 \pm 4.3 \mathrm{mg} /$ day versus $5.7 \pm 4.6 \mathrm{mg}$ day $(p=0.132)$. The total cumulative dose was significantly higher in $\mathrm{G} 1: 6.5 \pm 6.8$ $\mathrm{mg} /$ day versus $4.8 \pm 8.5 \mathrm{mg} / \mathrm{day}(p=0.025)$. There was no significant difference in using other DMARDs: Sulfasalazine $(\mathrm{p}=0.182)$ and leflunomide $(\mathrm{p}=0.276)$.

No significant difference was observed with patients under biologic DMARDs: $24.1 \%$ in $\mathrm{G} 1$ versus $17 \%$ in $\mathrm{G} 2$ ( $\mathrm{p}=0.725)$.

Conclusion: Cervical spine involvement is common in RA and may be asymptomatic. Immunopositive patients seem to have more frequently ADD, as well as those with high disease activity and severe structural joint damage. The treatment modalities do not appear to be affected by AAD; however, patients with ADD seem to have higher cumulative doses of corticosteroids and methotrexate. Given the cross-sectional nature of our study, it is difficult to confirm the connection between the two. Further studies are needed.

Disclosure of Interests: None declared

DOI: 10.1136/annrheumdis-2021-eular.4108

\section{AB0188 \\ DO PATIENT-REPORTED OUTCOMES IN RHEUMATOID ARTHRITIS REFLECT DISEASE ACTIVITY?}

K. Ben Abdelghani ${ }^{1}$, H. Boussaa ${ }^{1}$, S. Miladi ${ }^{1}$, M. Sellami ${ }^{1}$, L. Souabni ${ }^{1}$, S. Kassab ${ }^{1}$, S. Chekili ${ }^{1}$, A. Fazaa ${ }^{1}$, A. Laatar ${ }^{1} .{ }^{1}$ Mongi Slim University Hospital, Rheumatology, La Marsa, Tunisia

Background: Patient-reported outcomes (PROs) reflect the patient's perspective and are used in rheumatoid arthritis (RA) routine clinical practice. However, PROs may be associated with other aspects of health, such as psychological distress or comorbidities, which leads to situations of discordance with objective RA assessments.

Objectives: The aim of this study was to determine whether PROs were associated with objective assessment of disease activity.

Methods: We conducted a cross-sectional study including patients with RA (ACR/EULAR 2010). Demographic data were collected. The following PROs were assessed: number of nocturnal awakenings, morning stiffness duration, estimation of spontaneous pain and fatigue by Visual Analog Scale (VAS), and global patient assessment (GPA). In addition, patients rated their current satisfaction with their disease state according to the Austrian school mark system (PATSAT: $1=$ excellent, $2=$ good, $3=$ average, $4=$ moderate (fair), $5=$ unsatisfactory). Disease activity was assessed using the 28 -joint disease activity score with erythrocyte sedimentation rate (DAS28 ESR) and C reactive protein (DAS28 CRP). We used Cohen's kappa $(\kappa)$ to determine the agreement between PATSAT and DAS28 ESR. The $\kappa$ result was interpreted as follows: values $\leq 0$ as indicating no agreement and $0.01-0.20$ as none to slight, $0.21-0.40$ as fair, $0.41-0.60$ as moderate $0.61-0.80$ as substantial, and $0.81-1.00$ as almost perfect agreement. A p-value inferior to 0.05 was considered significant.

Results: We included 54 patients ( 45 women and nine men) with a mean age of $55 \pm 11$ years old [23-69]. The mean disease duration was $9.9 \pm 5.9$ years [0-20]. The mean number of nocturnal awakenings was $1.1[0-4]$ and the mean morning stiffness duration was 25.1 minutes [0-120]. The mean GPA was $5.3 \pm 2.2 \mathrm{~cm}$ $[0-10]$. The mean pain VAS was $5.4 \pm 2.2 \mathrm{~cm}[0-10]$ and the mean fatigue VAS was $4 \pm 2.5 \mathrm{~cm}[0-8]$. None of the patients described his disease state as 'excellent'. It was considered 'good' in $23.1 \%$ of cases, 'average' in $36.5 \%$ of cases, and 'moderate' to 'unsatisfactory' in $40.4 \%$ of cases. 